\title{
O Zooplâncton como ferramenta na popularização da ciência na comunidade escolar de Vila Bela da Santíssima Trindade-MT
}

A popularização de temas que envolvam o estudo de corpos d'água, ecossistemas aquáticos e seus organismos na educação básica, auxilia nas práticas e atitudes reflexivas do cidadão para a conservação e preservação do ambiente. A divulgação da ciência permite mostrar a sociedade resultados das pesquisas científicas realizadas ou em andamento. A realização de atividades dinâmicas por meio de oficinas pedagógicas é uma estratégia para integrar a teoria e prática. A proposta foi apresentar a Limnologia e ao zooplâncton do rio Guaporé para a comunidade escolar de Vila Bela da Santíssima Trindade-MT. Este estudo possui uma abordagem qualitativa de uma oficina com atividades práticas e lúdicas, caracterizadas por excursão a campo no rio coleta de amostras do zooplâncton, jogo da Mémoria e Trilha Limnológica. Durante a oficina, os participantes questionaram, mostraram-se interessados e surpresos com as informações ecológicas dos sistemas aquáticos, especialmente com a diversidade de organismos microscópicos existentes no sistema local. A motivação e o entusiasmo foram maiores com os jogos, por oferecer suspense e desafio nas cartas de perguntas e respostas. A expedição de campo proporcionou diálogos sobre as características do ecossistema aquático local e o reconhecimento de experiências espaciais e temporais. A oficina atuou como fonte de divulgação da pesquisa realizada e contribuiu para o conhecimento da biodiversidade aquática, a valorização cultural e biológica do rio Guaporé para a comunidade escolar do municipio.

\section{Zooplankton as tool in the science popularization at the school community of Vila Bela da Santíssima Trindade-MT}

\begin{abstract}
The popularization of themes in basic education that involve the study of water bodies, aquatic ecosystems and their organisms, aid in the reflective practices and attitudes of the citizen for the conservation and preservation of the environment. The dissemination of science allows showing the society the results of scientific researches carried out or under way. The realization of dynamic activities through pedagogical workshops is a strategy to integrate theory and practice. The proposal was to present the Limnology and the zooplankton of the Guaporé river the school community of the Vila Bela da Santíssima Trindade-MT. This study has a qualitative approach to a workshop with practical and playful activities, characterized by field trips in river, collection of zoop on system question and answer cards. The field expedition provided dialogues on the characteristics of the local aquatic ecosystem and the recognition of spatial and temporal experiences. The workshop acted as a source of popularization of research carried out and contributed to the knowledge of the aquatic biodiversity, the cultural and biological appreciation of the Guapore river for the school community of the municipality.
\end{abstract}

Keywords: Guaporé; Workshop; Playful Games

Topic: Educação Ambiental

Reviewed anonymously in the process of blind peer
Received: 02/02/2018

Approved: 20/05/2018
Carolina dos Santos

Universidade do Estado de Mato Grosso, Brasil http://lattes.cnpq.br/6821178591180153

http://orcid.org/0000-0001-8666-186X

carolsantosbio@hotmail.com

Carolina Joana da Silva (iD

Universidade do Estado de Mato Grosso, Brasil

http://lattes.cnpq.br/5253872582067659

http://orcid.org/0000-0003-0517-1661

ecopanta@terra.com.br

Alessandra Aparecida Elzanna Tavares Morini (iD Universidade do Estado de Mato Grosso, Brasil http://lattes.cnpq.br/9202818641485563

http://orcid.org/0000-0003-1158-3718

aetmorini@gmail.com

\author{
Wilkinson Lopes Lázaro (iD \\ Universidade do Estado de Mato Grosso, Brasil \\ http://lattes.cnpq.br/0263718697915954 \\ http://orcid.org/0000-0002-6499-6631 \\ wilkinsonlopes@gmail.com \\ Ítalo Silva Duarte (it) \\ Universidade Federal de Mato Grosso, Brasil \\ http://lattes.cnpq.br/0067339884964319 \\ http://orcid.org/0000-0001-5174-1202 \\ italo.fayra@gmail.com
}

Referencing this:

SANTOS, C.; SILVA, C. J.; MORINI, A. A. E. T.; LÁZARO, W. L.; DUARTE, I. S.. O Zooplâncton como ferramenta na popularização da ciência na comunidade escolar de Vila Bela da Santíssima Trindade-MT. Revista Ibero-Americana de Ciências Ambientais, v.9, n.1, p.188-196, 2018. DOI: http://doi.org/10.6008/CBPC2179-6858.2018.001.0013 


\section{INTRODUÇÃO}

O ensino e aprendizagem dos diversos conteúdos de Ciências Biológicas são garantidos pelos Parâmetros Curriculares Nacionais (PCNs), que reunem e conduzem propostas contextualizadas e dinâmicas a serem ofertadas na educação básica (BRASIL, 2000). Temas como Limnologia que estuda os corpos d'água continentais, organismos zooplanctônicos que exercem importante papel ecológico na cadeia alimentar aquática e a ecologia dos ecossistemas aquáticos e seus múltiplos usos, possibilita o desenvolvimento de habilidades, ações e valores que podem contribuir para atitudes reflexivas e práticas de conservação e preservação do ambiente (ESTEVES et al., 2011).

Para isso, popularizar e divulgar resultados de pesquisas cientificas, torna-se uma alternativa para difundir e aproximar o conhecimento da sociedade. Essa socialização, antes restritas a ambientes acadêmicos, é de fundamental importância para que o cidadão tenha noção dos fenômenos científicos, da atuação da ciência, de seus resultados, métodos e usos, desde os complexos até os mais simples (MOREIRA, 2006).

Segundo Correia et al. (2010) a realização de atividades dinâmicas pode ser uma estratégia de divulgação de trabalhos científicos que através de métodos demonstrativos e interativos pode ter a função de alfabetizar cientificamente a população, de forma que entendam o avanço e desenvolvimento da ciência.

As oficinas pedagógicas atuam na construção de conhecimento, através de práticas educativas, o que proporciona a integração da teoria e a prática. As atividades proporcionam autonomia, criatividade e socialização entre os participantes (VEJA et al., 2008). Segundo Nascimento et al. (2007) essas atividades são relevantes ferramentas na construção de conhecimentos teóricos e práticos de forma questionadora, com o uso de situações, histórias de vida e fatos da realidade vivenciada pelo público alvo, que resultam no processo de ensino aprendizagem participativo e reflexivo.

O desenvolvimento das oficinas pode ser intermediado por meio de músicas, produção de maquetes, painéis, jogos educativos que visa contribuir com o desenvolvimento cognitivo mais autônomo, por explorar as habilidades e competências do aluno (PERTICARRI et al., 2010).

Torres et al. (2003) considera o jogo didático como uma das principais bases da construção da relação da civilização, por excelência na comunicação, expressão e aprendizado. São fontes de recursos de ensino que favorecem as trocas de saberes e experiências entre os atuantes da prática lúdica.

Outra forma de difusão do conhecimento, é por meio das práticas de campo que oferecem subsídios de vários fatores naturais e instrumentos, que tornam o contato direto com o objeto de estudo insubstituíveis (SILVA et al. 2014). Essas dinâmicas de ensino em ambientes naturais podem subsidiar uma visão mais completa sobre as atuais problemáticas ambientais, proporcionando reflexão sobre a conservação e o uso sustentável do ecossistema, o que permite ao aluno tomar uma decisão e um posicionamento mais crítico em relação ao ambiente que o cerca (SGANZERLA et al., 2014).

Visto que para ações de conservação das comunidades biológicas e da manutenção dos ecossistemas aquáticos, é imprescindível conhecer a biodiversidade, a popularização dessa pesquisa, age como subsídio 
para reflexões sociais com o meio ambiente. Dessa forma, a proposta deste trabalho foi apresentar a Limnologia e ao zooplâncton do rio Guaporé para a comunidade escolar de Vila Bela da Santíssima TrindadeMT.

\section{METODOLOGIA}

\section{Área de estudo}

O estudo foi realizado na porção meridional da Amazônia Legal, no município de Vila Bela da Santíssima Trindade-MT, localizada na Mesorregião sudoeste deste estado, na bacia do Guaporé entre as coordenadas geográficas $16^{\circ} 15^{\prime} 58,51^{\prime \prime}$ e $14^{\circ} 00^{\prime} 20,79^{\prime \prime}$ de Latitude Sul e $59^{\circ} 54^{\prime} 19,16^{\prime \prime}$ e $60^{\circ} 23^{\prime} 11,64^{\prime \prime}$ de Longitude Oeste. Limita-se ao norte com o município de Comodoro, a leste com os municípios matogrossenses de Pontes e Lacerda, Conquista D' Oeste, Nova Lacerda e ao sul e Oeste com a Bolívia (IBGE, 2010). A bacia do Guaporé compreende uma área de $38.563,81 \mathrm{~km}^{2}$, formada por grandes rios e seus afluentes, sendo o principal, o rio Guaporé que nasce na Chapada dos Parecis-MT, a 630 metros de altitude ao encontrar o rio Mamoré na Bolívia (MOSS; MOSS, 2007). A dinâmica de campo foi realizada no perímetro urbano do rio Guaporé e amostrados em dois pontos denominados Volta da Prainha" e "Porto debaixo" (Figura 1).

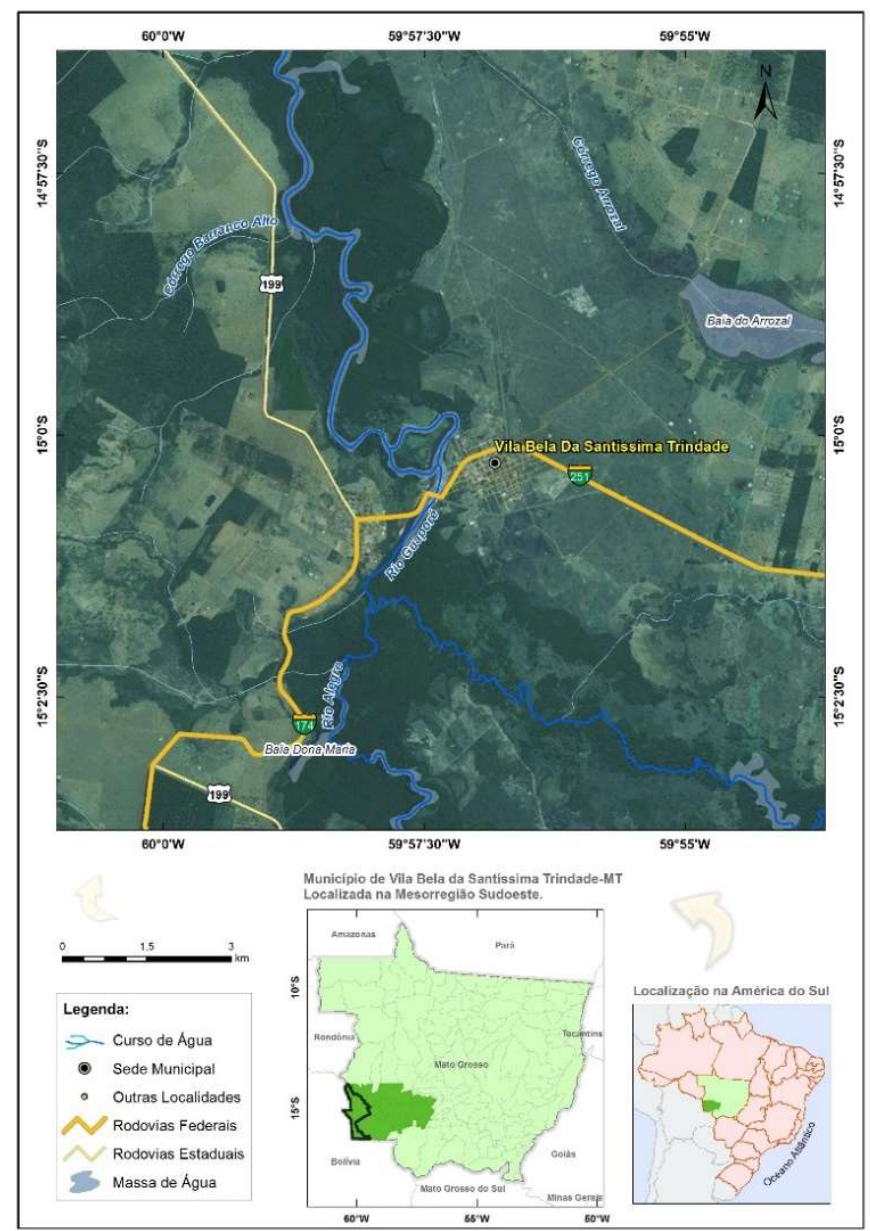

Figura 1. Área de estudo no município de Vila Bela da Santíssima Trindade-MT. Fonte: Acácio (2016). 


\section{METODOLOGIA}

As atividades realizadas atuaram como resposta de uma pesquisa de dissertação do Programa de Pós-Graduação em Ciências Ambientais-UNEMAT, integrado como parte do projeto "Conhecimento, uso sustentável e bioprospecção da biodiversidade na Amazônia Meridional" da Rede Bionorte, a comunidade escolar de Vila Bela da Santíssima Trindade-MT.

Este estudo possui uma abordagem qualitativa, descrita por Silveira e Córdova (2009), cuja metodologia se caracteriza pelo pesquisador ser fonte direta de contato com o ambiente de estudo, e dele se descrevem e se identificam fatores e fenômenos determinantes da pesquisa.

No período de 03 a 05 de junho de 2014, realizou-se uma oficina de 20h, intitulada "Águas do Guaporé", para alunos e professores do ensino médio da Escola Estadual "Verena Leite de Brito" e do ensino fundamental da Escola Municipal "Ricardo Franco". Os participantes eram de uma turma do 3ㅇ ano do ensino médio técnico integrado em Agroecologia (18 participantes) e uma turma do 70 e 8o ano do ensino fundamental ( 23 e 31 participantes respectivamente), no total de 71 pessoas.

A primeira etapa concentrou-se na apresentação sobre o ecossistema aquático local e das comunidades biológicas, com auxílio de recurso multimídia, palestras e uma cartilha didática sobre zooplâncton, com conteúdo de acordo com o nível escolar.

A segunda parte consistiu em uma expedição ao rio Guaporé que compreendeu observação, descrição do ambiente e a coleta de zooplâncton. As amostras foram coletadas em réplicas e filtradas em uma rede de plâncton com abertura de malha de 68 micra. A amostragem qualitativa foi realizada através de arrastos horizontais na sub-superfície da coluna d'água. O material foi acondicionado em frascos, fixados, conservados na solução de formol $4 \%$ e observados com o auxílio de lupas estereoscópicas, microscópios ópticos e identificados com referências bibliográficas recomendadas.

As variáveis limnológicas foram registradas com a Sonda multiparâmetro para a tomada de dados do $\mathrm{pH}$, temperatura, oxigênio dissolvido, oxigênio saturado, condutividade elétrica e turbidez. A transparência da água e profundidade da coluna da água total foram medidas com disco de Secchi. As amostras biológicas coletadas foram identificadas em sala de aula com a colaboração dos participantes.

No terceiro momento, aplicou-se dois jogos lúdicos, criados com o programa Corel Draw 4, impressos e plastificados. Os jogos abordaram sobre à Ecologia dos ecossistemas aquáticos regional, com foco na composição zooplanctônica.

Memória do Guaporé: caracterizado por um jogo composto por 36 cartas e operando como um jogo de memória comum; com cartas embaralhadas e colocadas sobre a mesa ou no chão, viradas para baixo. Na competição ganha quem descobrir mais pares de cartas correspondentes.

Trilha Limnológica: um jogo de tabuleiro, que comporta até 4 jogadores. Composto por 1 tabuleiro, 1 dado, 4 pinos (representando os jogadores), 35 cartões de pergunta-resposta, 30 cartas de curiosidades. Para iniciar, o primeiro participante faz um lance do dado e desloca-se no tabuleiro a quantia de casas respectivas ao número obtido. Ao parar em uma casa com algum comando, ele deve fazer o que está escrito na mesma. O vencedor será o primeiro a alcançar à casa escrita CHEGADA. 
A trilha é composta pelas seguintes casas e comandos: casa verde- carta de informação, curiosidade e continuar jogando; casa azul- avance o número de casas correspondente ao que pede; casa vermelhavolte o número de casas solicitadas no jogo; casa amarela- casa vazia, deverá permanecer nessa casa e passar a vez para o próximo jogador; casa laranja-deverá responder uma pergunta e seguir as regras citadas no tabuleiro.

\section{RESULTADOS}

Na primeira etapa, realizou-se uma apresentação dos participantes e do cronograma proposto. Logo após, ministrou-se uma palestra em sala de aula que abordou temáticas como a introdução a limnologia, origem, características dos corpos aquáticos, propriedades físico-químicas da água, conceitos, estrutura, importância de organismos aquáticos na cadeia trófica com enfoque no zooplâncton.

Durante a abordagem foi utilizado vídeos, slides com animações e diálogos com os participantes, que os estimulavam a interagir sobre os temas abordados, buscando conhecimento e comentários dos conceitos relacionados as informações apresentadas (Figura 2).

Na popularização da ciência, os recursos multimídias, atividades pedagógicas, usados na medida certa, são elementos eficazes que atuam como linguagem universal no processo de popularização científica (RENDEIRO; GONÇALVES, 2014). O recurso áudio visual também foi visto como de grande importância na oficina de Almeida et al. (2004) para professores com proposta de educação ambiental em praça pública, por chamar atenção de estudantes, aproximando-os da aprendizagem.

No decorrer da oficina, foram feitos questionamentos sobre o assunto trabalhado, sendo possível identificar que algumas das temáticas eram novas e outras não haviam sido trabalhadas profundamente, mostrando-se surpresos ao receber informações da ecologia dos sistemas aquáticos, principalmente dos sistemas locais e dos organismos microscópicos existentes. As informações, opiniões, conceitos explanados pelos participantes foram valorizados e enfatizados durante as palestras, pois estes demonstravam atenção aos assuntos com questionamentos, respostas e interesse em conhecer, dialogar e participar sobre o conteúdo em pauta.

Um texto didático foi distribuído com exercícios explicativos que seriam completados e corrigidos em sala de aula. No entanto, os participantes tiveram dificuldade em participar dos exercícios por ser tema novo, nunca trabalhado em sala de aula. Essas barreiras foram superadas após a prática de campo e atividade didática.

\section{Coleta de campo dos organismos zooplanctônicos}

A expedição a campo no rio Guaporé, proporcionou aos participantes a observação e o contato com os sistemas aquáticos locais. A turma foi dividida em grupos e levados aos locais de coletas em barcos. Durante a expedição dialogaram sobre as características limnológicas, identificando os locais de poucas correntezas (ambientes lênticos) e correntezas acentuadas (ambientes lóticos), observando a mata ciliar e as plantas aquáticas. Os participantes reconheceram moradias antigas, locais piscosos, habitats de vidas de 
jacarés, botos e tartarugas. Para alguns, a expedição propiciou a primeira viagem a este rio, para outros propiciou encontros e reconhecimento de vivências espaciais e temporais conectadas a suas histórias de vida.

Desta maneira, ocorreu na expedição o que Oliveira e Correia (2013) descreveram como a oportunidade que a aula a campo perpetua os mais diversos conhecimentos. Dependendo do tema, tem a possibilidade de trabalhar de forma interdisciplinar, pois abrange diversas áreas do ensino, transpondo a aprendizagem de aula teórica para a realidade vivenciada.

As observações e indagações foram além dos conteúdos ofertados, o que propicia aos participantes uma visão integrada a diversas áreas do conhecimento como história, geografia, biologia, matemática. Costa e Oliveira (2016) ressaltam que atividades bem planejadas fora do ambiente escolar atua na desmistificação de lugares públicos visto só como um ambiente de lazer, tornando o processo de ensino com maior significado.

A interação dos envolvidos com a dinâmica da aula foi maior quando o assunto era explicado de forma interligada a outras áreas educacionais, pois, segundo Boff e Pansera-de-Araújo (2011) "o ensino de ciência mostra a conexão com as outras áreas, uma vez que o conhecimento não é neutro e se constrói através do processo de interação entre os diferentes campos dos saberes".

Nesta premissa, o desenvolvimento das aulas de ciências e ecologia em ecossistemas naturais, permite ao aluno manifestar-se quanto as suas sensações, emoções que normalmente não se manifestariam em uma sala de aula. Seniciato e Cavassan (2004) verificaram em aula a campo no jardim botânico, que o ambiente natural conduz a uma atividade dinâmica, com abordagem da temática menos fragmentada, o que aproxima os alunos a indicar respostas mais próximas possíveis de conceitos científicos, proporcionada pela observação complexa e integral dos fenômenos naturais.

Ao coletar amostras de organismos zooplanctônicos e algumas variáveis físico-químicas, manusearam a rede de plâncton, aparelho multiparâmetro e disco de secchi. Após o campo, as amostras foram levadas a sala de aula, preparadas na lâmina de Sedgewick-Rafter e observadas em microscópio óptico e lupas estereoscópicas. Organizaram-se em filas e visualizaram as características específicas dos grupos coletados pelos mesmos. As existências dessas comunidades biológicas microscópicas eram desconhecidas aos alunos, os quais mostraram-se surpresos com a riqueza da vida invisível a "olho desarmado", o que propiciou desafios e motivações (Figura 2).
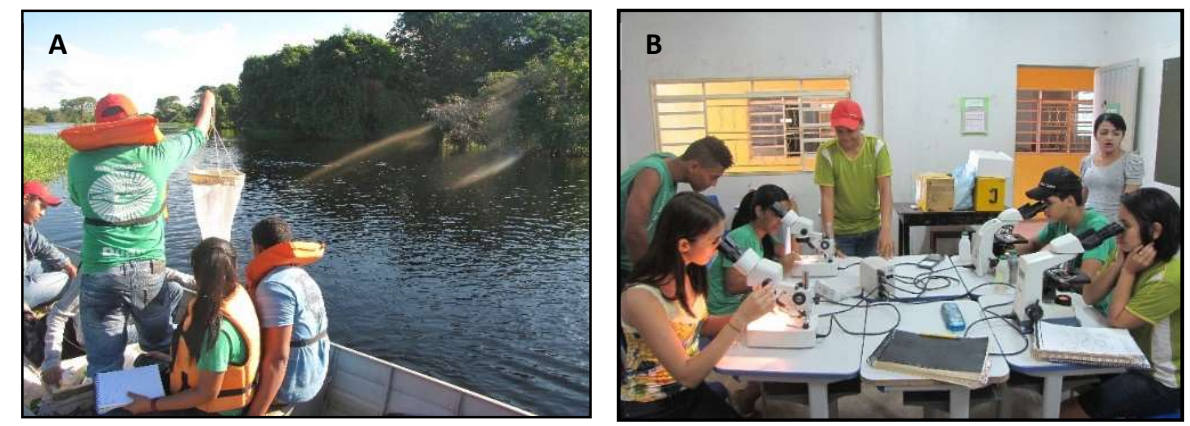

Figura 2. Atividades dinâmicas do campo. (a) Coleta no rio Guaporé; (b) Observação das amostras. 
Ao fim desta etapa, comentaram e dialogaram, discutindo que a experiência vivenciada poderia auxiliá-los na escolha de um curso de graduação. Além de afirmarem que ocorreu proporcionou o trabalho em equipe e fortalecimento dos laços entre professores e alunos.

Viveiro e Diniz (2009) afirmaram que a atividade em campo além de abstrair conteúdos, possibilita estreitar a relação de companheirismo entre professor e aluno, por resultar de uma experiência agradável e em comum entre os envolvidos, que perdura até ao ambiente escolar.

Tanto os alunos quanto aos professores disseram que a parceria da escola com a comunidade acadêmica deveria ser repetida outras vezes, como forma de inserção da sociedade escolar junto aos trabalhos científicos. Deste modo, Almeida et al. (2004) ressalta que a aproximação da universidade com a escola foi um fator de grande aprendizagem, de interesse de todos, como também demonstrado no presente estudo.

\section{Aplicação dos jogos didáticos}

Os jogos "Memória do Guaporé" e "Trilha Limnológica" apresentaram aspectos relacionados aos organismos zooplanctônicos, características e tipos de sistemas aquáticos para professores e alunos de ensino fundamental e médio técnico. A turma foi dividida em grupos e a eles explicada as regras das atividades lúdicas. Para cada dupla foi distribuído o jogo de mémoria, composto por cartas com imagens informativas e nomes do grupo de organismos zooplanctônicos no Rio Guaporé (Figura 3).
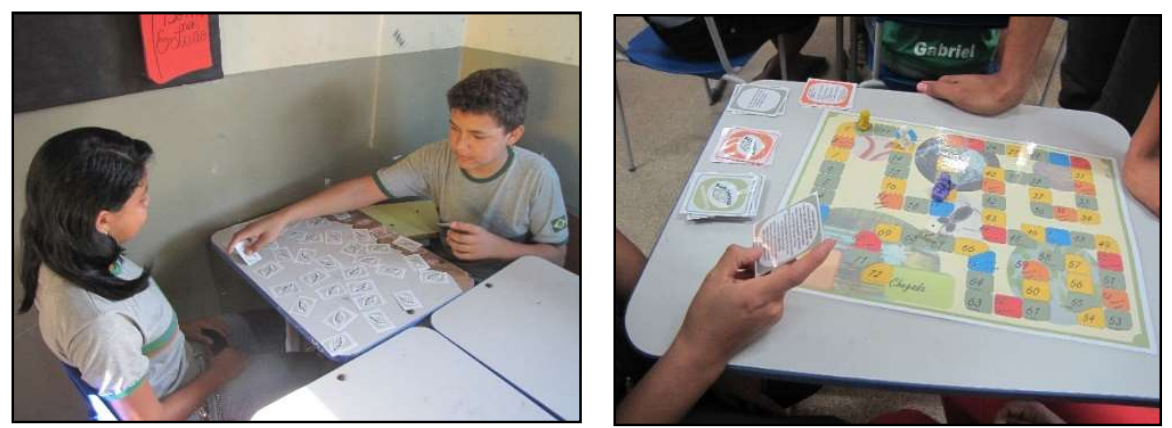

Figura 3. Jogos da oficina. (a) Trilha limnológica; (b) Memória do Guaporé.

No decorrer das rodadas demonstraram-se incentivados e entusiasmados. Observou-se companheirismo entre colegas que ajudavam um ao outro a responder as cartas de pergunta-resposta. Por mais conhecidos que sejam esses jogos, percebeu-se que não eram conhecidos por todos os participantes, com relatos de ser a primeira vez que praticavam o jogo da memória e tabuleiro. Dentre os jogos, a Trilha Limnológica teve maior repercussão, devido ao suspense e desafios das perguntas atuarem como um fator motivador externo para participação.

Ao final, os alunos relataram que os jogos os ajudaram a pensarem nas perguntas- respostas, nas novas informações das cartas e a relembrarem assuntos que haviam sido trabalhados, mas não profundamente. O nível de conhecimento e as mudanças adquiridas com a oferta da oficina pode ser verificado com o auxílio dos jogos. 
Conforme Oliveira e Saito (2014), o material didático tem potencial para serem usados em ações positivas na sociedade, e estimularem professores e alunos a trabalhar conteúdos de cunho socioambiental. Diniz et al. (2012) destacaram que metodologias dinâmicas são aliadas no processo de desenvolvimento de responsabilidades da sociedade para o meio ambiente que estão inseridos.

As atividades lúdicas foram ferramentas de incentivo para alcançar resultados no ensino aprendizagem durante a oficina. Esse método também foi utilizado por Moura e Santos (2014) em municípios do Mato Grosso no ensino de Biologia usando a ilustração de peixes e observaram nas atividades maior motivação dos participantes, principalmente após aprenderem as técnicas de produção de ilustração cientifica.

Candido e Ferreira (2012), ao desenvolver jogo didático para trabalhar com zoologia dos invertebrados com uma turma de ensino médio, constataram que esses recursos de entretenimento aliado a aprendizagem, proporcionam uma melhor aceitação de conteúdo por vezes desprestigiados no ambiente escolar pelas quantidades de informações, além de promover o contato direto com a temática.

As ações pedagógicas simples podem atuar na desmitificação sobre e de como são feitas as pesquisas desenvolvidas pela comunidade acadêmica. A oficina possibilitou uma interação da comunidade com o projeto, entendendo suas ações, resultados, possibilitando a eles serem partícipes no processo de ensino aprendizagem no contexto da popularização da ciência.

Atividades como essas podem ser facilmente replicadas, adequando as turmas escolares, pois segundo Almeida et al. (2004) a interação e observação dos alunos com o espaço social e natural, pode ser estimulada, a partir de oficinas que os próprios professores podem desenvolver ativamente com seus alunos.

\section{CONSIDERAÇÕES FINAIS}

Ao socializar os resultados da pesquisa de dissertação, iniciou-se o processo de divulgação e popularização da ciência do ecossistema aquático e do zooplâncton trabalhado no rio Guaporé com a comunidade escolar de Vila Bela da Santíssima Trindade.

As atividades lúdicas proporcionaram a formação de diferentes relações de grupos e promoveu o envolvimento do participante com o objeto de estudo, estreitando a relação da comunidade acadêmica com a escolar. A oficina atuou como excelente fonte de popularização de resultados de pesquisas realizadas pela comunidade acadêmica junto a sociedade, dando transparência e visibilidade ao projeto de pesquisa desenvolvido na comunidade.

AGRADECIMENTOS: Este trabalho teve o suporte financeiro do projeto: “Conhecimento, uso sustentável e bioprospecção da biodiversidade da Amazônia Meridional" (MCTIC, CNPq-554330/2010-5; FAPEMAT205983/2011). A CAPES pela bolsa de estudos a primeira autora. 


\section{REFERÊNCIAS}

ALMEIDA, L. F.R.; BICUDO, L.R H.; BORGE, G.L.A. Educação ambiental em praça pública: relato de experiência com oficinas pedagógicas. Ciência \& Educação, v. 10, n. 1, p. 121132, 2004.

BRASIL. Parâmetros curriculares Nacionais. Ministério da Educação. Brasília, 2000.

BOFF, E.T.O.; PANSERA- DE-ARAÚJO, M. C. A significação do conceito energia no contexto da Situação de Estudo: Alimentos - produção e consumo. Revista Brasileira de Pesquisa em Educação em Ciências, v. 11, n. 1, p. 123-142, 2011.

CANDIDO, C.; FERREIRA, J.F. Desenvolvimento de material didático na forma de um jogo para trabalhar com zoologia dos invertebrados em sala de aula. Cadernos da Pedagogia, São Carlos, Ano 6, v. 6 n. 11, p. 22-33, 2012.

CORRÊA, D.M.V.B.; SILVA-JÚNIOR, E.F. Ciência vai à escola: o lúdico na educação em ciências. In: Portal Educacional do estado do Paraná. 2016.

COSTA, S.A.; OLIVEIRA, L.M.M. O jardim zoológico como espaço para o ensino de mamíferos: tecendo uma estratégia investigativa. Revista da SBEnBio, v. 3, n.9, p. 127-138, 2016.

DINIZ, L.P.; BRITO, M.T.S.; CORDEIRO, W.P F.S.; MELO, A.L.; MELO-JÚNIOR, M. "A fauna está acabando, a camada de ozônio está furada”. Percepção e conscientização ambiental por crianças de duas escolas públicas do sertão de Pernambuco. Revista Eletrônica do Mestrado em Educação Ambiental, v. 29, p. 1-15, 2012.

ESTEVES, F.A. História da Limnologia brasileira e seus desafios nas primeiras décadas do século XX. In: Francisco de Assis Esteves. (Org.). Fundamentos de Limnologia. 3a ed. Rio de Janeiro: Interciência, 2011, p. 523-580.

INSTITUTO BRASILEIRO DE GEOGRAFIA E ESTATÍSTICA (IBGE). Bases e referenciais, 2010. 2010

MOREIRA, I.C. A inclusão social e a popularização da ciência e tecnologia no Brasil. Inclusão Social, Brasília, v. 1, n. 2, p. 11-16, 2006.

MOSS, G.; MOSS, M. Projeto Brasil das Águas-Sete Rios: revelando o azul do verde e amarelo. Guaporé, Brasília, D.F, 62p, 2007.

MOURA, N.A.; SANTOS, E.C. Ensino de biologia usando a ilustração de peixes para alunos do ensino médio, graduandos e professores da rede pública de três municípios do estado de Mato Grosso. Em extensão, Uberlândia, v. 13, n.2, p.70-78, 2014.

NASCIMENTO, M.S.; SANTOS, F.P.A.; RODRIGUES, V.P.; NERY, V.A.S. Oficinas pedagógicas: construindo estratégias para a ação docente -relato de experiência. Rev.Saúde.Com, v.3, n.1, p. 85-95, 2007.

OLIVEIRA, A.P.L.; CORREIA, M.D. Aula de Campo como mecanismo facilitador do ensino-aprendizagem sobre os ecossistemas Recifais em Alagoas. Alexandria: Revista de Educação em Ciência e Tecnologia, Santa Catarina, v. 6, n. 2, p.163-190, 2013.

OLIVEIRA, E.G.; SAITO, C.H. Análise do material didático PROBIO-educação ambiental com foco na transversalidade curricular do tema meio ambiente. Revista Brasileira de Educação Ambiental, São Paulo, v. 9, n. 2, p.225-238, 2014.

PERTICARRARI, A.; TRIGO, F.R.; BARBIERI, M.R.; COVAS, D.T. "O uso de textos de divulgação científica para o ensino de conceitos sobre Ecologia à estudantes da Educação Básica". Ciência \& Educação, São Paulo, v. 16, n. 2, p. 369-386, 2010.

RENDEIRO, M.F.B.; GONÇALVES, C.B. Divulgação e popularização da ciência: relato de experiência do projeto "Ciência às 7 e meia". Rev. ARETÉ, Manaus, v. 7, n. 13, p. 222-231, 2014.

SENICIATO, T.; CAVASSAN, O.. Aulas de campo em ambientes naturais e aprendizagem em ciências - um estudo com alunos do ensino fundamental. Ciência \& Educação, v. 10, n. 1, p. 133-147, 2004.

SILVA, L.M.; SANTOS, V.V.; GERTRUDES, F.A.L. Biologia na aula de campo: reconhecendo a interdisciplinaridade através da visita ao Geopark Araripe. Revista Sapiência: sociedade, saberes e práticas educacionais, v.3, n. 2, p.143-157, 2014.

SILVEIRA, D. T.; CÓRDOVA, F.P. Unidade 2- A pesquisa científica. In: GERHARDT, T. E.; SILVEIRA, D. T.. Métodos de Pesquisa. Porto Alegre: Editora da UFRGS, p. 31-42, 2009.

SGANZERLA, G.C.; FERNANDEZ, F.R.B.; MIANI, C.S. Representações de estudantes do ensino fundamental sobre a diversidade dos seres vivos. Revista da SBEnBio, n.7, p. 2629-2639, 2014.

TORRES, H.C.; HORTALE, V.A.; SCHALL, V. A experiência de jogos em grupos operativos na educação em saúde para diabéticos. Cad. Saúde Pública, Rio de Janeiro, v. 19, n.4, p. 1039-1047, 2003.

VIVEIRO, A.A.; DINIZ, R.E.S. Atividades de campo no ensino das ciências e na educação ambiental: refletindo sobre as potencialidades desta estratégia na prática escolar. Ciência em Tela, v. 2, n. 1, p. 1-12, 2009.

VEGA, L.B.S.; SCHIRMER, S.N. Oficinas Ecopedagógicas: transformando as práticas educativas diárias nos anos iniciais. Rev. Eletrônica do Mestrado em Educação Ambiental, v. 20, 2008.

A CBPC - Companhia Brasileira de Produção Científica (CNPJ: 11.221.422/0001-03) detém os direitos materiais desta publicação. Os direitos referem-se à publicação do trabalho em qualquer parte do mundo, incluindo os direitos às renovações, expansões e disseminações da contribuição, bem como outros direitos subsidiários. Todos os trabalhos publicados eletronicamente poderão posteriormente ser publicados em coletâneas impressas sob coordenação da Sustenere Publishing, da Companhia Brasileira de Produção Científica e seus parceiros autorizados. Os (as) autores (as) posteriormente ser publicados em coletâneas impressas sob coordenação da Sustenere Publishing, da Companhia Brasileira de Produção Científica e seus parce
preservam os direitos autorais, mas não têm permissão para a publicação da contribuição em outro meio, impresso ou digital, em português ou em tradução. 